\title{
Is By-catch Mortality Preventing the Rebuilding of Cod (Gadus morhua) and American Plaice (Hippoglossoides platessoides) Stocks on the Grand Bank?
}

\author{
Peter A. Shelton and M. Joanne Morgan \\ Northwest Atlantic Fisheries Centre, Department of Fisheries and Oceans \\ P. O. Box 5667, St John's, Newfoundland, Canada A1A 5X1
}

Shelton, P. A., and M. J. Morgan. 2005. Is by-catch mortality preventing the rebuilding of cod (Gadus morhua) and American Plaice (Hippoglossoides platessoides) stocks on the Grand Bank? J. Northw. Atl. Fish. Sci., 36: 1-17. doi: 10.2960/J.v36.m544

\begin{abstract}
Cod (Gadus morhua) and American plaice (Hippoglossoides platessoides) on the Grand Bank of Newfoundland supported substantial commercial fisheries for extensive periods in the past. Both stocks declined and have been under fisheries moratoria since 1994, but continue to be harvested as by-catch in other directed fisheries on the Grand Bank. For each stock, a precautionary spawning stock biomass limit reference point $\left(B_{\text {lim }}\right)$ has been established by the Scientific Council of the Northwest Atlantic Fisheries Organization. In this study, stochastic simulations were used to evaluate the probability distributions of the time horizons required to rebuild each of the two stocks to above $B_{\text {lim }}$. A range of by-catch mortality levels, recruitment models, and body growth and maturation rates were applied in the simulations. Uncertainty in the estimates of the numbers at age in the last assessed year and uncertainty in future recruitment were also incorporated within the simulations. If by-catches are not substantially reduced, the modelling results indicate there is virtually zero probability of attaining $B_{\text {lim }}$ by 2020 for either the cod or American plaice stocks on the Grand Bank.

Key words: American plaice, by-catch, cod, collapse, precautionary approach, rebuilding, recruitment, stochastic simulation, spawning stock biomass.
\end{abstract}

\section{Introduction}

By-catch mortality (non-targeted fishing mortality) has emerged as a major problem in the management of marine fish stocks (Alverson et al., 1994; Crowder and Murawksi, 1998; Hall et al., 2000). Much of the focus has been on discarding, species selectivity of fishing gear, and the lack of reliable statistics. However, the impact of unsustainable by-catch on stocks at low levels of abundance or facing extinction (Musick et al., 2000; Hall, 1996) is perhaps even more important. Little attention has been given to situations where the by-catch species has equal or greater economic value than the targeted species and is therefore seldom discarded. In these cases, an economic incentive exists for fisheries to maximise by-catch within the regulations, and to seek ways of increasing or exceeding by-catch limits. This can significantly impact the rebuilding of depleted populations. Recent collapses of groundfish stocks in the Northwest Atlantic (Atkinson, 1994; Sinclair and Murawski, 1997), followed in some cases by little or no rebuilding and continued fishing by vessels ostensibly in pursuit of other species, highlight the importance of accounting for by-catch mortality.

Two of the most historically important groundfish stocks on the Grand Bank of Newfoundland (Fig 1) are Atlantic cod (Gadus morhua) in NAFO (Northwest Atlan- tic Fisheries Organization) Divisions 3NO and American plaice (Hippoglossoides platessoides) in Divisions 3LNO. Landings in the $3 \mathrm{NO}$ cod fishery peaked at 227000 tons in 1967 (Fig. 2) while estimated spawning stock biomass (SSB) peaked in 1965 at about 125000 tons (Stansbury et al., MS 2001; Fig. 3). Landings in the 3LNO plaice fishery peaked at about 94000 tons in 1967 (Fig. 2) when SSB was estimated to be about 240000 tons (Morgan et al., MS 2002; Fig. 3). With the subsequent decline in SSB in both stocks, recruitment declined to record low levels (Fig. 3).

Both stocks collapsed in the late-1980s and early1990s, and were placed under moratoria on directed fishing in 1994. To facilitate stock rebuilding, NAFO imposed by-catch limits on both stocks. By-catches of each stock were not to exceed $1250 \mathrm{~kg}$ or $5 \%$ of the total catch (by weight) of all species caught in any single fishing set - whichever was greater (NAFO, 2004). Although the moratoria on the directed fisheries for both stocks have continued to the present, recent assessments have indicated a "creeping by-catch mortality" problem (Stansbury et al., MS 2001; Healey et al., MS 2003; Morgan et al., MS 2002, 2003) as a result of the Grand Bank fisheries for skate (Raja spp.), yellowtail flounder (Limanda ferruginea) and Greenland halibut (Reinhardtius hippoglossoides). 


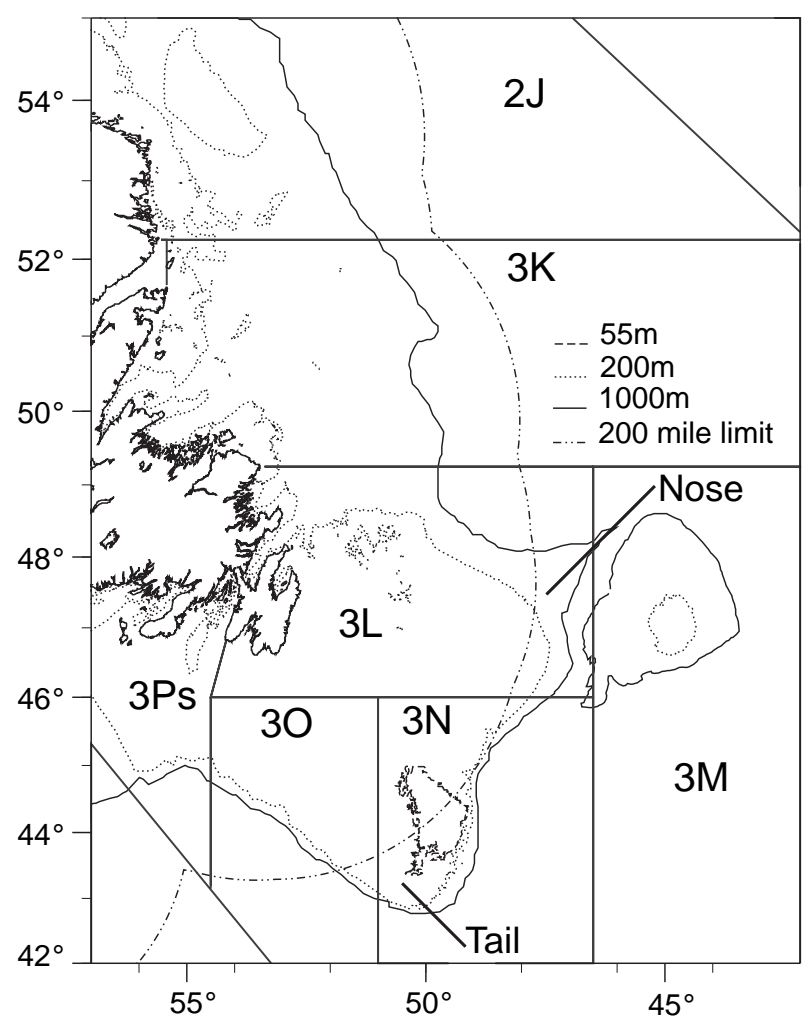

Fig. 1. Map of the study area showing the various Northwest Atlantic Fisheries Organization (NAFO) Divisions. The 55, 200 and $1000 \mathrm{~m}$ depth contours are shown along with Canada's 200 naut. mile zone. The two stocks in the study are American plaice in Div. 3L, 3N and $3 \mathrm{O}$ and cod in Divisions 3N and $3 \mathrm{O}$.

The scientific advice from the NAFO Scientific Council to the Fisheries Commission in recent years has been that continued by-catch at recent levels will prevent rebuilding of the cod and American plaice stocks. However, there has been little analysis of the conditions necessary for stock rebuilding. In particular, there has been no exploration of the effect of different levels of stock productivity with respect to weights and maturities and only limited exploration of differing levels of recruitment and fishing mortality (Rivard et al., MS 1999; Morgan et al., MS 2002; NAFO, 2003). In this study, we attempt to provide a more comprehensive answer to the question, "is by-catch mortality preventing the rebuilding of the 3NO cod and 3LNO plaice stocks on the Grand Bank?" by taking into account stock productivity conditions.

For both the 3NO cod and the 3LNO plaice, the NAFO Scientific Council has established limit reference points on SSB $\left(B_{\text {lim }}\right)$ below which stock-recruit models
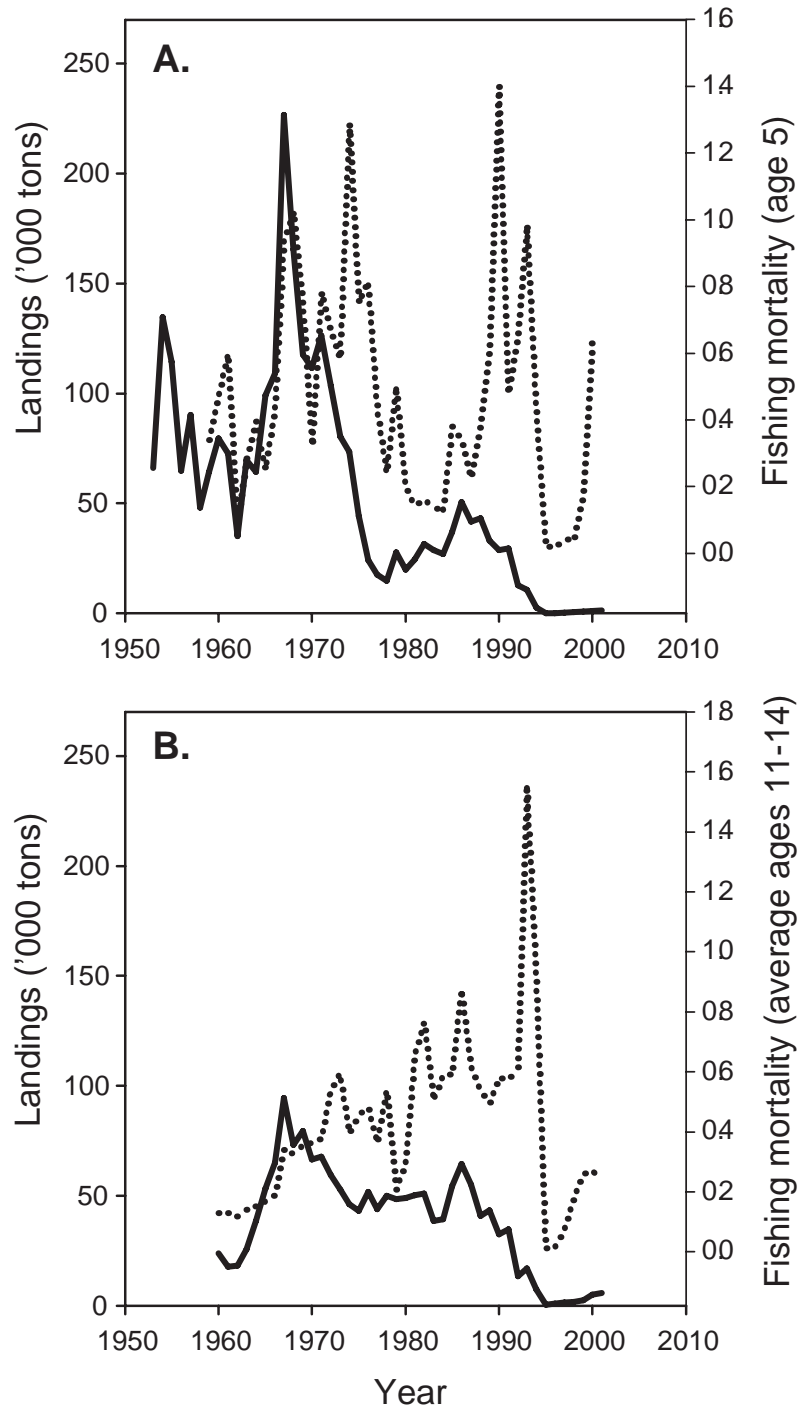

Fig. 2. Landings (solid line) in thousands of metric tons and fishing mortality (dotted line) for (A) $3 \mathrm{NO}$ cod and (B) 3LNO American plaice. Landings are defined here as reported catch, by-catch, and NAFO estimates of unreported catch.

and visual inspection of stock-recruit data indicate there is a high probability of poor recruitment. $B_{\text {lim }}$ for $3 \mathrm{NO}$ cod was set at 60000 tons and for 3LNO plaice at 50000 tons of SSB (Anon., MS 2003). It is intended that directed fisheries will not reopen until there is confidence that SSB has increased to the point where it exceeds $B_{l i m}$.

While it is common practice in short-term projections to assume that processes such as recruitment, growth and maturation rates remain constant for brief periods in the future, such assumptions may not be valid for longer-term simulations. Previous studies have examined rebuilding times for Grand Bank cod and American plaice using 

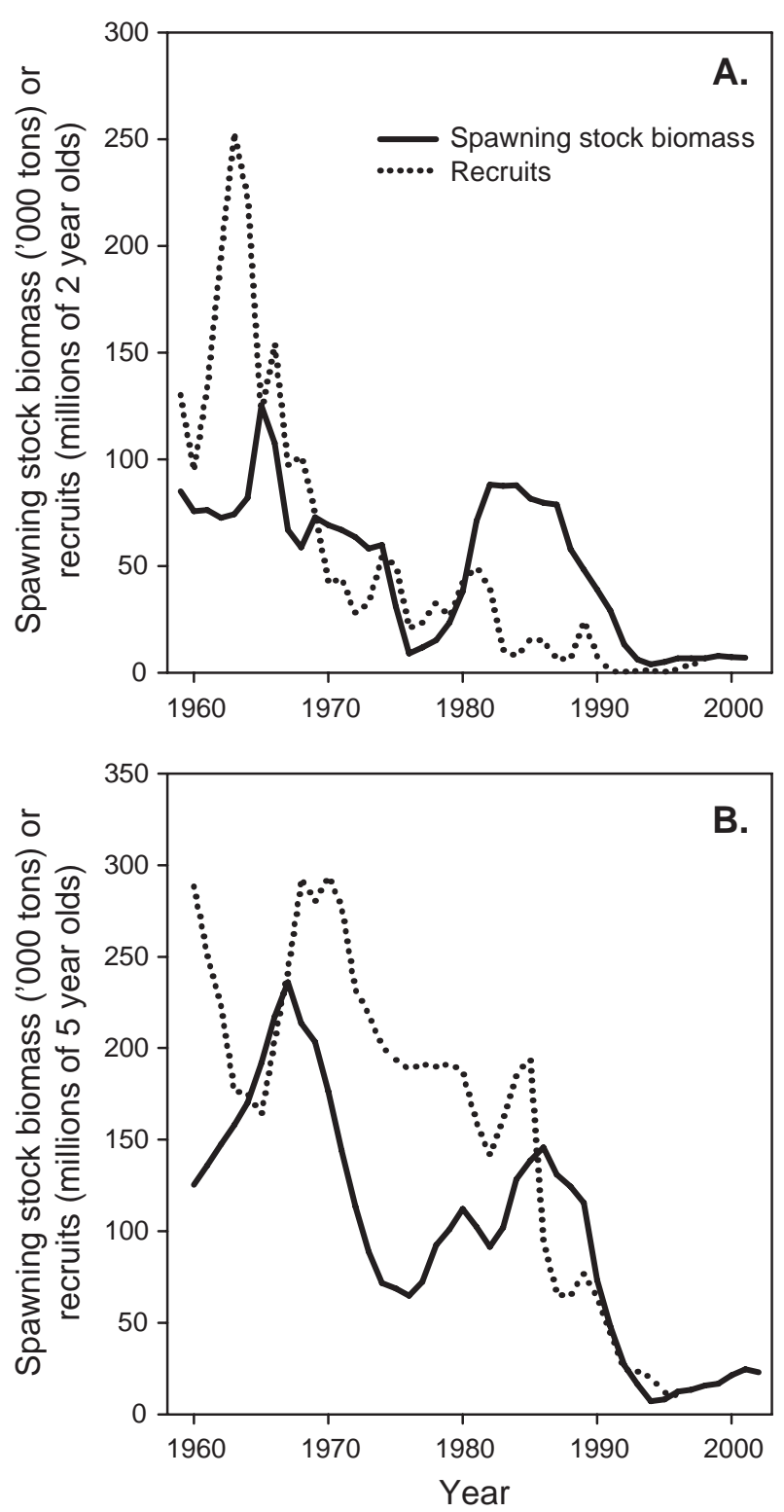

Fig. 3. Spawning stock biomass (solid line) and recruits (dotted line) for (A) 3NO cod and (B) 3LNO American plaice.

medium to long-term simulations (Rivard et al., MS 1999; Morgan et al., MS 2002, MS 2003; Healey et al., MS 2003). These studies applied recent average weights and maturities-at-age, and used either stochastic recruitment or fixed recruitment rates based on recent averages. In this study, we explicitly examine population growth under different levels of stock productivity as affected by different recruitment rates, body growth rates and maturation rates to determine the conditions under which rebuilding might occur. We compare our results to previous studies that did not account for changes in stock productivity.
Our analyses are based on the data in Stansbury et al. (MS 2001) and Morgan et al. (MS 2002). Subsequent to our analyses, updated assessments have been conducted for both stocks (Healey et al., MS 2003; Morgan et al., MS 2003). We compare the inputs applied in our analyses with the data in these more recent assessments to evaluate whether our conclusions on stock rebuilding are still valid.

\section{Materials and Methods}

A series of simulations were performed using estimates of population numbers and fishing mortality at age from recent stock assessments of 3NO cod and 3LNO plaice accepted by the NAFO Scientific Council (Stansbury et al., MS 2001; Morgan et al., MS 2002). The simulations were conducted to the year 2020 and employed a range of assumptions on recruitment, weight-at-age and female proportion mature-at-age. Three fishing mortality rate $(F)$ scenarios were considered: $F=0$ implying no by-catch; $F=1 / 2$ recent implying $50 \%$ by-catch reduction, and $F=$ recent implying status quo by-catch. Fully recruited fishing mortality (calculated as the average of the most recent two years in the respective assessments) was 0.409 for $3 \mathrm{NO}$ cod and 0.255 for 3LNO plaice.

The simulations consisted of age structured forward projections that accounted for uncertainty in initial population sizes, and included either fixed recruitment rates, or stochastic recruitment based on variation around fitted kernel smoother or Beverton-Holt models. All other processes in the simulations were treated in a deterministic manner. The projections were similar to those described in Shelton (1998) and commonly used in NAFO groundfish stock assessments (e.g. Morgan et al., MS 2002, MS 2003; Healey et al., MS 2003). The population model applied in the simulation was:

$$
N_{a+1, y+1}=N_{a, y} e^{-\left(M+F_{a, y}\right)}
$$

where $N_{a, y}$ is the number alive at age $a$ and the beginning of year $y, M$ is the annual instantaneous rate of natural mortality and $F_{a, y}$ is the fishing mortality on age $a$ in year $y$, obtained from:

$$
F_{a, y}=K_{a} F_{y}
$$

where $K_{a}$ is the partial recruitment value at age $a$ and $F_{y}$ is the fully recruited fishing mortality in year $y$. For 3NO cod, $a=2$ to 12 with no plus group. For 3LNO plaice, $a=$ 5 to 15 , where age 15 is a plus group, which was updated in the simulation by applying:

$$
N_{15, y+1}=N_{14, y} e^{-\left(M+F_{14, y}\right)}+N_{15, y} e^{-\left(M+F_{15, y}\right)}
$$


Spawning stock biomass at the beginning of year $y$ was calculated as:

$$
S S B_{y}=\sum{ }_{a} N_{a, y} W_{a, y} P_{a, y}
$$

where $P_{a, y}$ is the proportion mature-at-age $a$ in year $y$ and $W_{a, y}$ is the population weight-at-age $a$ at the beginning of year $y$.

As in the NAFO Scientific Council assessments of the two stocks (Stansbury et al., MS 2001; Morgan et al., MS 2002), weights-at-age were derived from commercial catch samples and maturities-at-age were estimated from research vessel survey samples. Although weights-at-age derived from commercial sampling can be biased by size selective fishing patterns, commercial and survey weights were positively correlated indicating that changes in commercial weights-at-age reflect changes in the population rather than changes in gear selectivity. Because weights derived from commercial samples were available over a longer time series and had a greater distribution across seasons than survey weight samples, they were used in the simulations. Beginning of year population weights-at-age $W_{a, y}$ were obtained by assuming that average annual commercial catch weights-at-age $(C W)$ pertain to mid-year, and computed from:

$$
W_{a, y}=G M\left(C W_{a, y}, C W_{a-1, y-1}\right)
$$

where $G M$ is the geometric mean, following the approach outlined in Rivard (1982). Estimates of $P_{a, y}$ were derived by fitting a cohort maturation model to survey sample data (Morgan, MS 2000).

Estimates of population numbers-at-age for the historical period up to the start of the simulation were obtained from sequential population analysis (SPA), specifically ADAPT (Gavaris, MS 1988). The population estimates were provided in Stansbury et al. (MS 2001) and Morgan et al. (MS 2002). Variances and covariances of the estimates (representing the error in the population model fit to abundance indices) were obtained from the ADAPT output and used to describe the uncertainty in the initial population size at the start of the simulation period.

The simulations consisted of 30 separate trials of 1000 runs each for each stock. Trials were conducted using three different recruitment models (fixed recruitment rate, random recruitment with the probability determined by kernel smoother weighting, and random recruitment drawn from a lognormal distribution around a fitted Beverton-Holt model), three levels of stock productivity (low, median and high), and three levels of fishing mortality ( $F=0, F=1 / 2$ recent, and $F=$ recent). A trial was also performed under each recruitment model using recent stock productivity with $F=$ recent to provide a baseline.
"Recent" was defined as the average of the last two years of available data from the 2001 assessment of 3 NO cod and the 2002 assessment of 3LNO plaice, rather than an average of a longer period because of the increasing trend in $F$ observed in both assessments. A single trial therefore represented 1000 runs of the simulation model for a specific combination of recruitment model, stock productivity level, and $F$.

The four levels of stock productivity were computed in terms of spawning stock biomass (kg) per recruit (SPR) at $F=0$ and $M=0.2$ using historic values of weights- and maturities-at-age as provided in the stock assessments. The levels of SPR were based on low ( $10^{\text {th }}$ percentile), median ( $50^{\text {th }}$ percentile), high $\left(90^{\text {th }}\right.$ percentile $)$ and recent (average of last two years in the respective assessments) weights and maturities at age (Fig. 4 and 5) relative to recruitment at age 2 for $3 \mathrm{NO}$ cod and at age 5 for 3LNO plaice (Tables 1 and 2). Recent mean weights-at-age were relatively high, up to age 7 for $3 \mathrm{NO}$ cod but low from age 9 onwards (Fig. 4a), and close to the median at all ages for 3LNO plaice (Fig. 4b). Recent values of proportion mature-at-age were slightly higher than the $90^{\text {th }}$ percentile for $3 \mathrm{NO}$ cod (Fig. 5a) and close to the $90^{\text {th }}$ percentile for 3LNO plaice (Fig. 5b). Recent SPR at $F=0$ was intermediate between low and median historic values for 3NO cod, and between median and high historic values for 3LNO plaice (Table1).

In the fixed recruitment rate simulations, recruits (thousands of fish) per spawning stock biomass (RPS) [measured in metric tons] were computed from assessment estimates of spawning stock biomass and recruits. Four RPS levels were computed: low, median, high and recent, based on the $10^{\text {th }}, 50^{\text {th }}$ and $90^{\text {th }}$ percentiles and the average of the last two year-classes in the assessments, respectively (Table 1; Fig. 6). RPS for 3 NO cod has been low since the early-1980s (Fig. 6a), and has fluctuated widely in recent years for 3LNO plaice (Fig. 6b). Recent RPS for both stocks was between low and median historic values (Table 1).

In the random recruitment trials based on the kernel smoother, recruitment values were randomly resampled from previously observed values weighted by a Gaussian probability density function $\omega$, where

$$
\omega=\frac{1}{h \sqrt{2 \pi}} \exp \left(-\frac{d^{2}}{2 h^{2}}\right)
$$

and where $h=$ the smoothing window and $d=$ the difference between the spawning stock biomass (SSB) value at which recruitment is to be predicted and the SSB corresponding to the recruitment for which the weighting is being computed, using the approach of Rice and Evans 


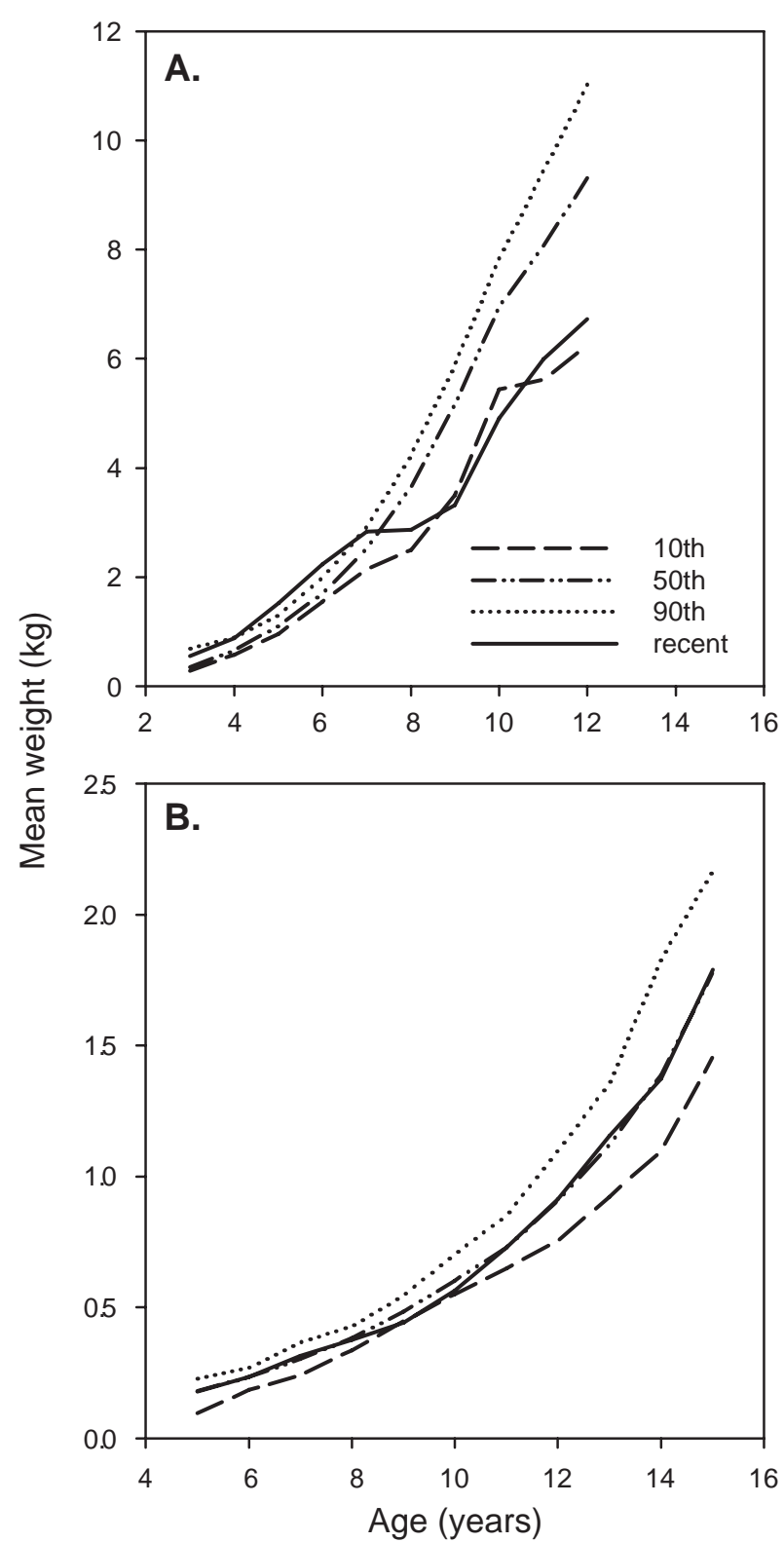

Fig. 4. Population mean weights-at-age (kg) for (A) $3 \mathrm{NO}$ cod and (B) 3LNO American plaice.

(1988). Estimates of the smoothing window $h$ (found by minimizing the cross-validated prediction sums of squares where the predictor is the kernel weighted mean) are listed in Table 1. The Beverton-Holt model was formulated as

$$
R=\frac{\alpha S}{1+(S / K)} \varepsilon
$$

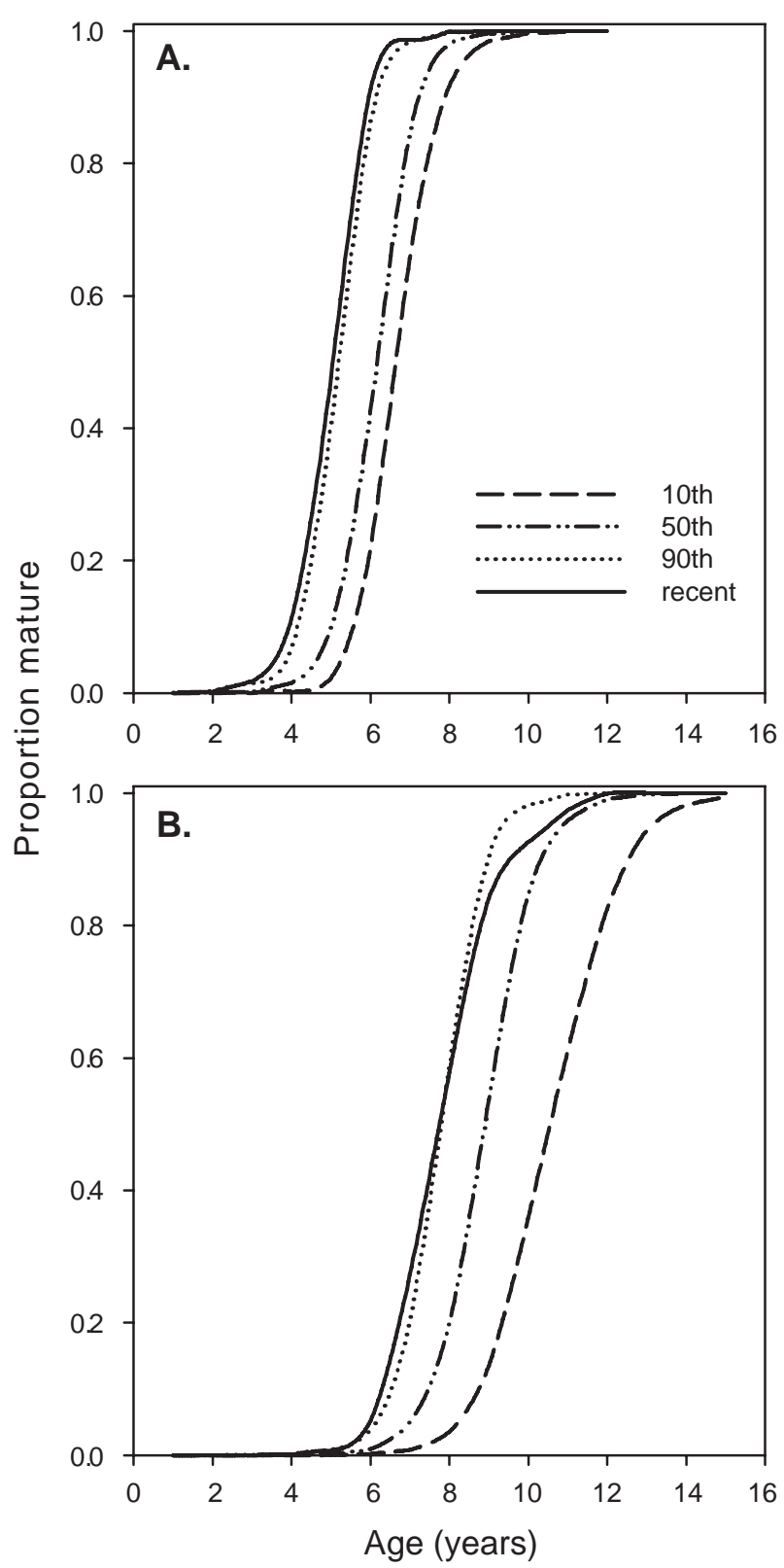

Fig. 5. Estimated proportion mature-at-age for (A) 3NO cod and (B) 3LNO American plaice.

where $R$ is recruitment, $S$ is spawning stock biomass, $\varepsilon$ is a multiplicative lognormal error term with mean $=$ 1 and variance $=\sigma^{2}$, and $a, K$ and $\sigma$ are parameters to be estimated. The model was fit to historic data using the maximum likelihood approach described in Myers et al. (1995). Parameter estimates are given in Table 1. In the random recruitment trials using the Beverton-Holt model, 
TABLE 1. Inputs for the simulation trials for 3NO cod and 3LNO American plaice.

\begin{tabular}{lrr}
\hline \hline & Cod & American plaice \\
\hline Fixed recruitment rate (RPS) & & \\
Low & 0.09 & 0.76 \\
Median & 0.67 & 1.46 \\
High & 2.17 & 2.70 \\
Recent & 0.61 & \\
Gaussian kernel smoother & & \\
Shape parameter (h) & 19834 & \\
Beverton-Holt & & \\
$\alpha$ & 1.14 & \\
K & 9.24 & \\
$\sigma$ & 1013 & \\
Spawning stock biomass per recruit (SPR) (kg) & 1.23 & \\
Low & & 1.45 \\
Median & 5.089 & 2.499 \\
High & 7.520 & 3.215 \\
Recent & 9.528 & 2.635 \\
\hline
\end{tabular}

recruitment values were randomly drawn from the lognormal distribution defined by $\sigma^{2}$ around the model-predicted value of $R$ corresponding to the simulated SSB value.

Recruitment estimates from the three different recruitment models are plotted in Fig. 7. For $3 \mathrm{NO}$ cod, the asymptote of the Beverton-Holt model, $\alpha K$, is unrealistically large indicating that there is little information on compensation in the data. The kernel smoother and Beverton-Holt models predict recruitment for $3 \mathrm{NO}$ cod which exceeds that predicted by the median historic RPS over the range of the data (Figs. 7a and 7c). For 3LNO plaice, the Beverton-Holt model predicts recruitment above the median RPS for SSB values below about 200 000 tons, while the kernel smoother model predicts recruitment above the median RPS for SSB values below about 150000 tons. The tendency for the two models to over-predict recruitment relative to median historic RPS (particularly at low stock sizes) results in more optimistic rebuilding times in the simulations.

For both stocks, $M$ was assumed constant at 0.2 in all trials, the value used in recent assessments. In reality, $M$ may vary considerably over time - as thought to have previously occurred in 3LNO plaice (Morgan and Brodie, MS 2001; Morgan et al., MS 2002) - and this variability can have a major impact on SPR. Varying $M$ in the simulations would require recomputing the historic population sizes in the SPA for each value of $M$, and would lead to changes in the spawner-recruit relationships. Rebuilding simulations that account for uncertainty in $M$ should be explored, but were beyond the scope of the present study.

\section{Results}

For both cod and plaice, results from the fixed recruitment rate trials at low and recent RPS and SPR levels indicate zero probability of rebuilding to above $B_{\text {lim }}$ by 2020 even at $F=0$. There is a small probability $(<0.20)$ of $3 \mathrm{NO}$ cod rebuilding to above $B_{\text {lim }}$ by 2020 at $F=1 / 2$ recent at median RPS and SPR, but zero probability for 3LNO plaice (Fig. 8). Both stocks are predicted to rebuild to above $B_{\text {lim }}$ at $F=0$ under median productivity levels, but the probability of this occurring before 2010 is very low. Rebuilding to above $B_{\text {lim }}$ is predicted to occur at recent $F$ levels if RPS and SPR are high, but the probability of this occurring before 2010 is also low. The probability of exceeding $B_{\text {lim }}$ by 2010 at high productivity levels increases to 1.0 in both stocks if fishing mortality is reduced to $1 / 2$ the recent level or is zero. At these high productivity levels, the 0.5 cumulative probability of exceeding $B_{\text {lim }}$ is reached about one year earlier for $3 \mathrm{NO}$ cod and about two years earlier for 3LNO plaice at $F=0$ compared to $F=1 / 2$ recent.

Under recent $F$ levels at low SPR, results from the random recruitment trials using the non-parametric kernel smoother model suggest a very low probability of exceeding $B_{\text {lim }}$ for $3 \mathrm{NO}$ cod by 2020 and a negligible probability of exceeding $B_{\text {lim }}$ by 2020 for 3LNO plaice (Fig. 9). These probabilities increase to above 0.6 for 
TABLE 2. Age specific values of population weight, catch weight, maturity and partial recruitment used in the simulations to represent low, medium, high, and recent productivity conditions.

\begin{tabular}{|c|c|c|c|c|c|c|c|c|c|c|c|c|}
\hline \multicolumn{13}{|c|}{ Age } \\
\hline State & Variable & 2 & 3 & 4 & 5 & 6 & 7 & 8 & 9 & 10 & 11 & 12 \\
\hline \multicolumn{13}{|c|}{ 3NO Cod } \\
\hline \multirow[t]{3}{*}{ Low } & Population weight & 0.000 & 0.278 & 0.579 & 0.962 & 1.550 & 2.146 & 2.497 & 3.502 & 5.439 & 5.614 & 6.251 \\
\hline & Catch weight & 0.000 & 0.546 & 0.879 & 1.519 & 2.230 & 2.834 & 2.867 & 3.315 & 4.914 & 5.989 & 6.726 \\
\hline & Maturity & 0.000 & 0.000 & 0.002 & 0.023 & 0.218 & 0.657 & 0.916 & 0.984 & 0.996 & 0.999 & 1.000 \\
\hline \multirow[t]{3}{*}{ Medium } & Population weight & 0.000 & 0.351 & 0.657 & 1.102 & 1.700 & 2.522 & 3.647 & 5.166 & 6.952 & 8.069 & 9.308 \\
\hline & Catch weight & 0.000 & 0.546 & 0.879 & 1.519 & 2.230 & 2.834 & 2.867 & 3.315 & 4.914 & 5.989 & 6.726 \\
\hline & Maturity & 0.000 & 0.002 & 0.015 & 0.100 & 0.425 & 0.846 & 0.980 & 0.996 & 1.000 & 1.000 & 1.000 \\
\hline \multirow[t]{3}{*}{ High } & Population weight & 0.000 & 0.689 & 0.888 & 1.300 & 1.991 & 2.917 & 4.228 & 5.899 & 7.836 & 9.438 & 11.028 \\
\hline & Catch weigth & 0.000 & 0.546 & 0.879 & 1.519 & 2.230 & 2.834 & 2.867 & 3.315 & 4.914 & 5.989 & 6.726 \\
\hline & Maturity & 0.003 & 0.015 & 0.070 & 0.405 & 0.864 & 0.983 & 0.998 & 1.000 & 1.000 & 1.000 & 1.000 \\
\hline \multirow[t]{5}{*}{ Recent } & Average 1999-2000 & & & & & & & & & & & \\
\hline & Population weight & 0.000 & 0.479 & 0.640 & 1.177 & 1.856 & 2.406 & 2.531 & 2.991 & 4.593 & 6.017 & 6.498 \\
\hline & Catch weight & 0.000 & 0.546 & 0.879 & 1.519 & 2.230 & 2.834 & 2.867 & 3.315 & 4.914 & 5.989 & 6.726 \\
\hline & Maturity & 0.002 & 0.018 & 0.113 & 0.477 & 0.912 & 0.986 & 0.999 & 1.000 & 1.000 & 1.000 & 1.000 \\
\hline & $\begin{array}{l}\text { Partial recruitment } \\
\text { Average 1999-2000 }\end{array}$ & 0.034 & 0.335 & 0.878 & 1.000 & 0.399 & 0.313 & 0.303 & 0.219 & 0.280 & 0.172 & 0.183 \\
\hline \multicolumn{13}{|c|}{ 3LNO American plaice } \\
\hline & & 5 & 6 & 7 & 8 & 9 & 10 & 11 & 12 & 13 & 14 & $15^{+}$ \\
\hline \multirow[t]{3}{*}{ Low } & Population weight & 0.096 & 0.185 & 0.241 & 0.336 & 0.446 & 0.551 & 0.648 & 0.756 & 0.923 & 1.097 & 1.454 \\
\hline & Catch weight & 0.203 & 0.298 & 0.371 & 0.439 & 0.516 & 0.657 & 0.829 & 1.056 & 1.305 & 1.503 & 2.022 \\
\hline & Maturity & 0.000 & 0.002 & 0.008 & 0.035 & 0.135 & 0.358 & 0.611 & 0.825 & 0.943 & 0.982 & 0.994 \\
\hline \multirow[t]{3}{*}{ Medium } & Population weight & 0.182 & 0.234 & 0.302 & 0.383 & 0.484 & 0.603 & 0.728 & 0.908 & 1.120 & 1.389 & 1.776 \\
\hline & Catch weight & 0.203 & 0.298 & 0.371 & 0.439 & 0.516 & 0.657 & 0.829 & 1.056 & 1.305 & 1.503 & 2.022 \\
\hline & Maturity & 0.002 & 0.009 & 0.050 & 0.199 & 0.537 & 0.846 & 0.958 & 0.991 & 0.998 & 1.000 & 1.000 \\
\hline \multirow[t]{3}{*}{ High } & Population weight & 0.227 & 0.270 & 0.366 & 0.428 & 0.545 & 0.704 & 0.850 & 1.098 & 1.355 & 1.828 & 2.167 \\
\hline & Catch weight & 0.203 & 0.298 & 0.371 & 0.439 & 0.516 & 0.657 & 0.829 & 1.056 & 1.305 & 1.503 & 2.022 \\
\hline & Maturity & 0.008 & 0.038 & 0.205 & 0.589 & 0.907 & 0.982 & 0.998 & 1.000 & 1.000 & 1.000 & 1.000 \\
\hline \multirow[t]{5}{*}{ Recent } & Average 2000-01 & & & & & & & & & & & \\
\hline & Population weight & 0.178 & 0.235 & 0.316 & 0.377 & 0.442 & 0.565 & 0.728 & 0.912 & 1.154 & 1.374 & 1.790 \\
\hline & Catch weight & 0.203 & 0.298 & 0.371 & 0.439 & 0.516 & 0.657 & 0.829 & 1.056 & 1.305 & 1.503 & 2.022 \\
\hline & Maturity & 0.007 & 0.052 & 0.273 & 0.578 & 0.841 & 0.926 & 0.974 & 0.999 & 1.000 & 1.000 & 1.000 \\
\hline & $\begin{array}{l}\text { Partial recruitment } \\
\text { Average } 2000-01\end{array}$ & 0.029 & 0.117 & 0.327 & 0.502 & 0.713 & 0.813 & 1.000 & 1.000 & 1.000 & 1.000 & 1.000 \\
\hline
\end{tabular}

3NO cod and to about 0.2 for 3LNO plaice when $F=1 / 2$ recent and approaches 1.0 when $F=0$. For both stocks, the probability of rebuilding to above $B_{\text {lim }}$ before 2010 is less than 0.5 at low SPR even when $F=0$. If $F$ remains at recent levels, the probability of rebuilding to above $B_{\text {lim }}$ by 2020 is less than 0.5 for both stocks at median SPR levels. Reducing $F$ to $1 / 2$ the recent level increases the probability of exceeding $B_{\text {lim }}$ by 2020 to above 0.8 for both stocks, but the probability of this occurring before 2010 is less than 0.5 . If by-catch mortality is eliminated entirely (i.e., $F=0$ ), then the probability of rebuilding to above $B_{\lim }$ before 2010 is higher than 0.5 for both stocks, and is 1.0 with respect to exceeding $B_{\text {lim }}$ by 2020 . At high SPR, the probability of rebuilding to above $B_{\text {lim }}$ by 2020 is above 0.8 at recent $F$ levels for both stocks. Using recent SPR levels and recent $F$, the kernel smoother simulation results indicate a probability of less than 0.5 for $3 \mathrm{NO}$ cod but above 0.8 for 3LNO plaice of attaining $B_{\text {lim }}$ by 2020 .

The results obtained from the random recruitment trials using a Beverton-Holt model (Fig. 10) are broadly similar to those obtained from the kernel smoother simu- 


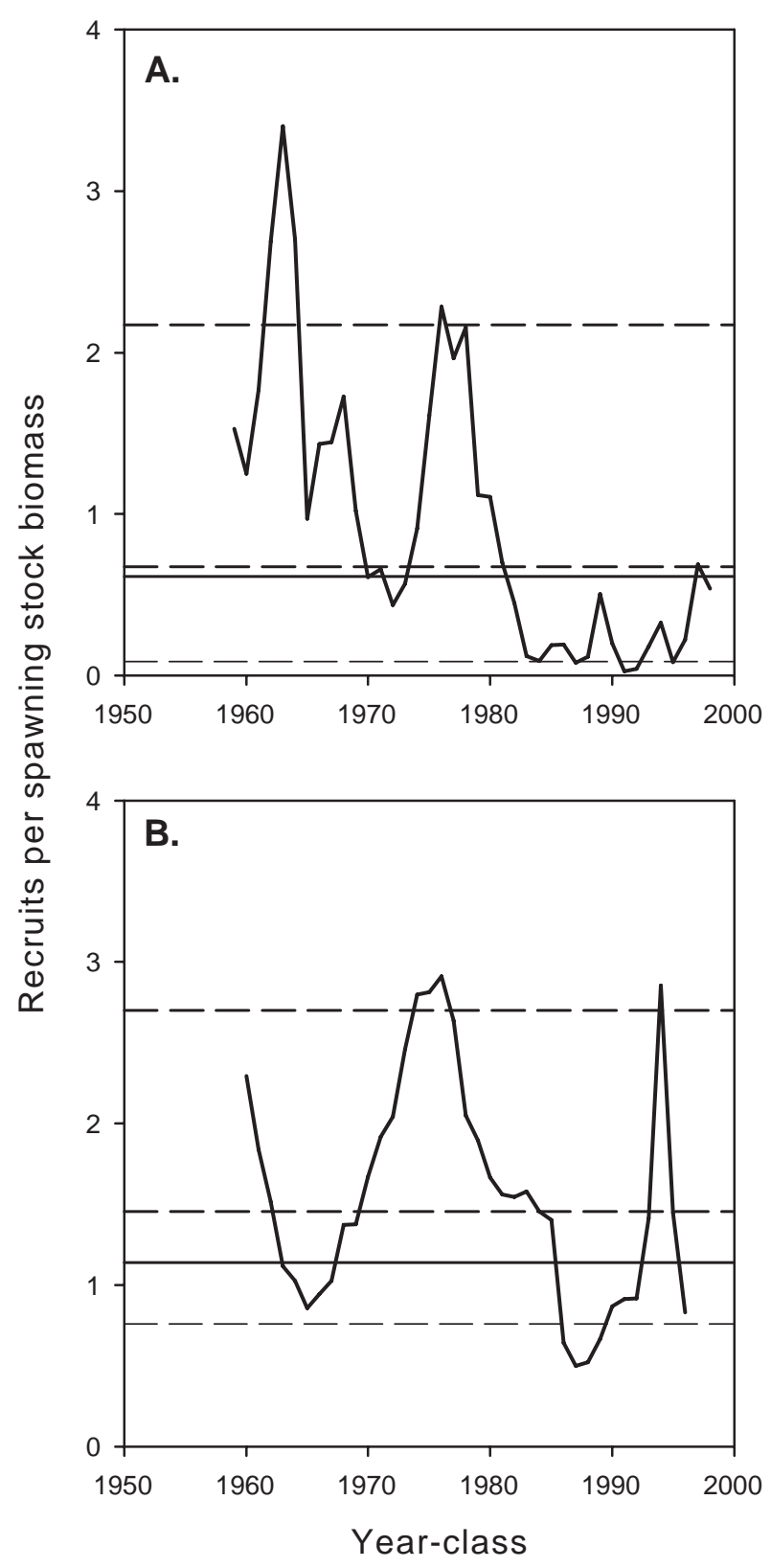

Fig. 6. Recruits per spawning stock biomass (in thousands of recruits per metric ton of spawning stock biomass) for each year-class at age 2 for (A) 3NO cod, and at age 5 for (B) 3LNO American plaice. The dashed horizontal lines indicate the $10^{\text {th }}, 50^{\text {th }}$ and $90^{\text {th }}$ percentiles while the solid horizontal line indicates the average recruits per spawning stock biomass for the last two year-classes.

lations. For $3 \mathrm{NO}$ cod, the cumulative probability profiles are almost identical at $F=0$ but are shifted somewhat to the left (higher probability of earlier rebuilding to above $B_{\text {lim }}$ ) at $F=1 / 2$ recent and $F=$ recent compared to the kernel smoother results. For 3LNO plaice, the results at $F=0$ are shifted slightly to the right (later attainment of $B_{\text {lim }}$ ) using the Beverton-Holt model compared to the kernel smoother model. The kernel smoother model is more optimistic than the Beverton-Holt model with respect to the time required for the $3 \mathrm{LNO}$ plaice stock to reach $B_{\lim }$ at $F=1 / 2$ recent, and $F=$ recent.

The recent assessments of Healey et al. (MS 2003) and Morgan et al. (MS 2003) provide updated values for recruitment, fishing mortality, growth, and maturity-at-age for 3NO cod and 3LNO plaice. We compare these values with those used in this study (Fig. 11). For 3NO cod, the 2003 assessment gives a considerably more pessimistic view regarding current recruitment rates as compared to the 2001 assessment. The value used to represent recent RPS for the cod stock in this study (0.61 - the average based on the two most recent year-classes in the 2001 assessment) is substantially higher than a similarly computed value from the 2003 assessment. Consequently, the estimates of time to rebuild to $B_{\text {lim }}$ for the $3 \mathrm{NO}$ cod stock in this study may be overly optimistic. For 3LNO plaice, the 2003 assessment is very similar to the 2002 assessment. RPS is slightly higher for the most recent year-class (1997 cohort) and the 2003 assessment indicates a slight reduction in fully recruited $F$. Although there are slight changes in both stocks in the weights-at-age and proportions mature-at-age used in the two assessments, the effects on SPR are minimal. For 3NO cod, SPR is slightly higher $(+12 \%)$ based on the 2003 assessment data (7.070 kg per age 2 recruit) than the 2001 assessment data used in this study (6.297 kg per age 2 recruit). For 3LNO plaice, SPR using data from the 2003 assessment (2.587 kg per age 5 recruit) is slightly lower (-2\%) than the value used in this study to represent recent SPR (2.635 kg per age 5 recruit). Overall, conditions do not appear to have changed sufficiently for either stock to render the conclusions drawn in this paper invalid.

\section{Discussion}

Under a precautionary approach to fisheries management, directed fishing on a depleted stock may be prohibited in the interests of conservation and stock rebuilding. However, directed fisheries on co-occurring species can result in by-catch. In these cases, it is common for a by-catch allowance to be made to facilitate the directed fishery while still allowing for rebuilding of the depleted stock. If the by-catch species is of lesser value than the directed species, there may be little incentive to use the entire allowance. However, when the by-catch species is economically equal or greater in value than the target species, an incentive exists to maximize or exceed the by-catch limit depending on the expected repercussions 

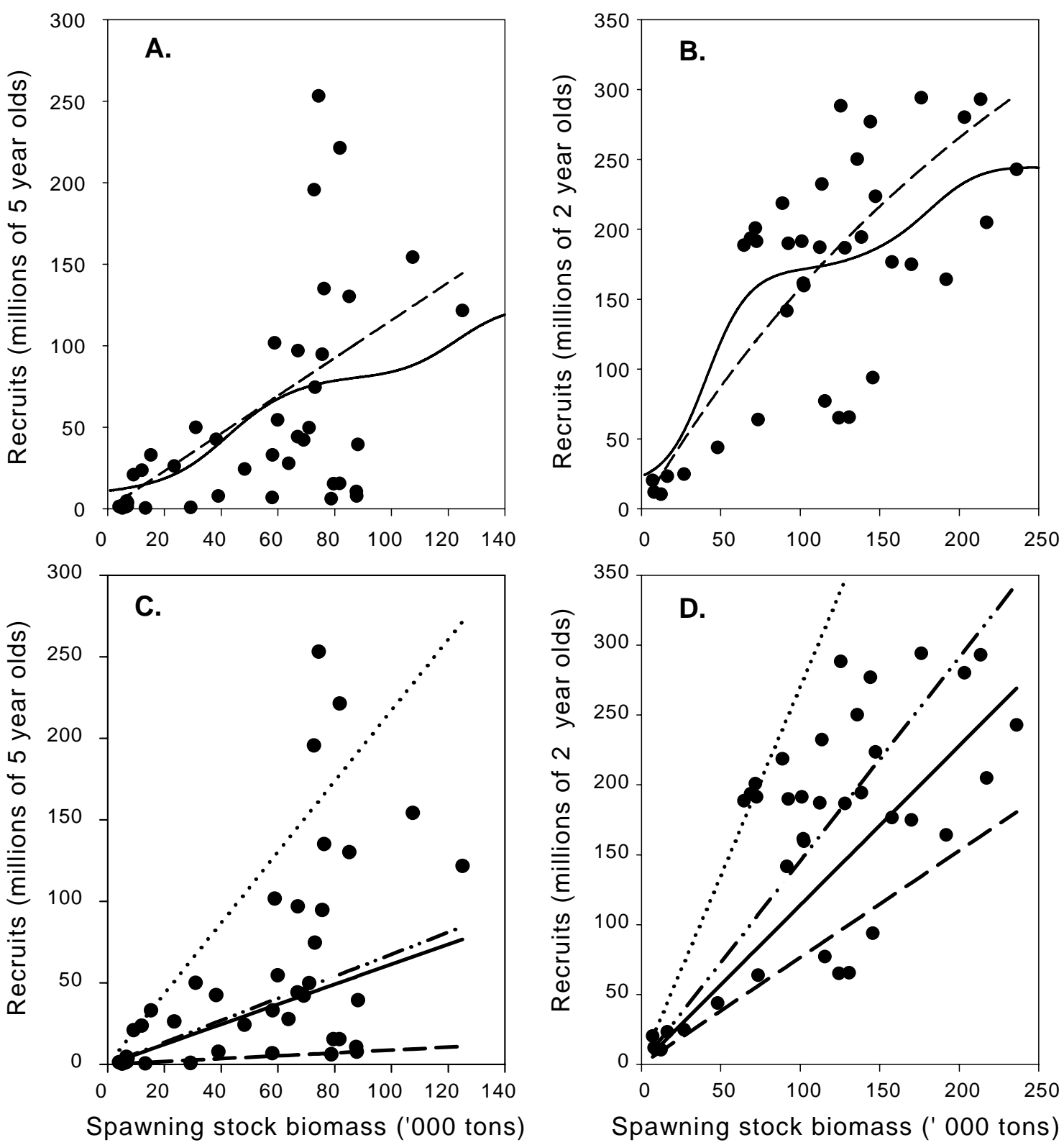

Fig. 7. Recruitment in millions of recruits $(\bullet)$ at various levels of beginning of the year spawning stock biomass (in thousands of metric tons). Estimated recruitment from a kernel smoother (solid line) and a Beverton-Holt stock recruit model (dashed line) are given for (A) cod and (B) American plaice. Estimated recruitment from different levels of recruits per spawning stock biomass is also given for (C) cod and (D) American plaice. The $10^{\text {th }}$ percentile (dashed line), $50^{\text {th }}$ percentile (dashed and dotted line), $90^{\text {th }}$ percentile (dotted line) and the recent (solid line) level of recruits per spawning stock biomass are plotted. Spawning stock biomass corresponding to $B_{\text {lim }}$ is 60000 tons for 3NO cod, and 50000 tons for 3LNO American plaice.

(Ackley and Heifetz, 2001). NAFO has implemented conservation and enforcement measures (CEM) (NAFO, 2004) in the NAFO Regulatory Area (NRA, here refers to the Nose and Tail of the Grand Bank) aimed at limiting by-catch on a number of depleted groundfish stocks to promote rebuilding. Similarly, the Coastal State, Canada, has imposed by-catch limits on groundfish stocks inside 200 naut. miles. Southern Grand Bank cod and Grand Bank American plaice are stocks that are under moratoria, on directed fishing, but fish from these stocks can be legally caught and retained as by-catch in other directed fisheries on the Grand Bank. 


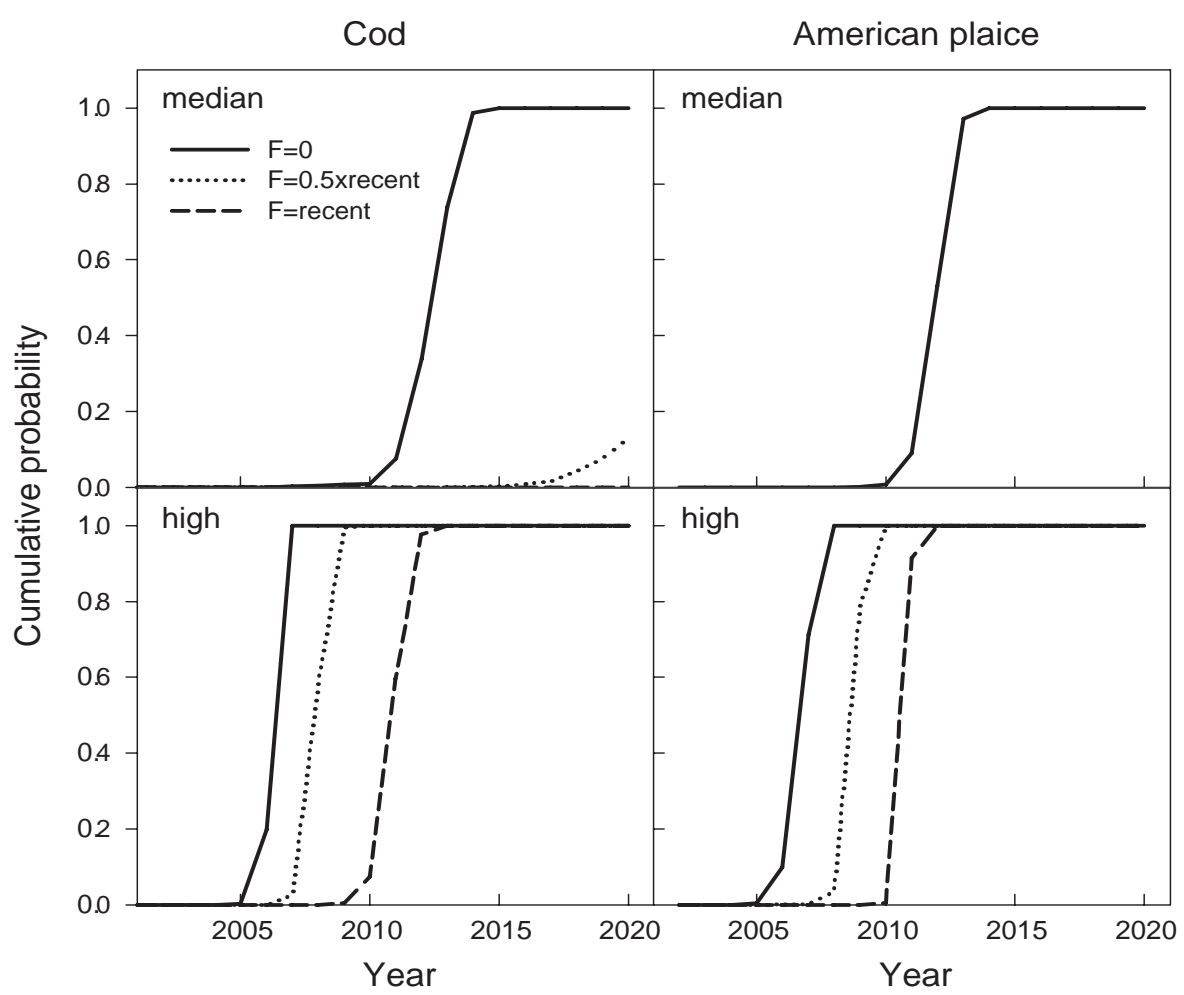

Fig. 8. The cumulative probability of the population exceeding $B_{\lim }$ in each year at medium and high levels of spawning stock biomass per recruit and recruit per spawner spawning stock biomass for cod and American plaice. Simulations were also run at recent and low levels of spawning stock biomass and recruit per spawning stock biomass for both species, but none of the trials reached $B_{\lim }$ by 2020 .

The enforcement of the NAFO by-catch restrictions, i.e., that by-catch should not exceed $1250 \mathrm{~kg}$ or $5 \%$ of the total catch in any one haul (NAFO, 2004) has met with limited success. On average, about $60 \%$ of the southern Grand Bank cod by-catch has been taken in the NRA over the last few years (Stansbury et al., MS 2001). By-catch of $3 \mathrm{NO}$ cod in fisheries directed at other species has apparently been generally low (less than 5\% overall), although some fishing trips have generated very high percentage of by-catches (del Rio and Junquera, MS 2001; del Rio et al., MS 2002, MS 2003; Vargas et al., MS 2003, MS 2004). Inside Canada's 200 naut. mile zone, by-catch of southern Grand Bank cod is reported to be generally less than $5 \%$, but has sometimes been higher, for example 30\% overall in the directed skate directed fishery in 1999 (Canadian Department of Fisheries and Oceans, official catch statistics (unpubl. data).
In recent years, by-catches of 3LNO plaice have been dominated by catches outside the 200 naut. mile zone, although there was a large increase in the percentage of the by-catch taken inside Canada's zone in 2001 (Morgan et al., MS 2002). The main source of American plaice by-catch in Canadian waters is the fishery directed for yellowtail flounder. This fishery had greater than $5 \%$ by-catch overall in 2000 and greater than 10\% in 2001 (Kulka, MS 2002). There is also a by-catch of American plaice in the directed fishery for Greenland halibut inside the 200 naut. mile zone. Estimates of 3LNO plaice by-catch in the skate directed fishery conducted by Spain in the NRA ranged between 12 and 14\% during 1998-2001 and was slightly over 5\% in 2002 (NAFO, 2003 p. 175; del Rio and Junquera, MS 2003). Large by-catches of 3LNO plaice have also occurred in the Portuguese directed skate fishery in the NRA (Vargas et al., MS 2003, MS 2004). Given these 


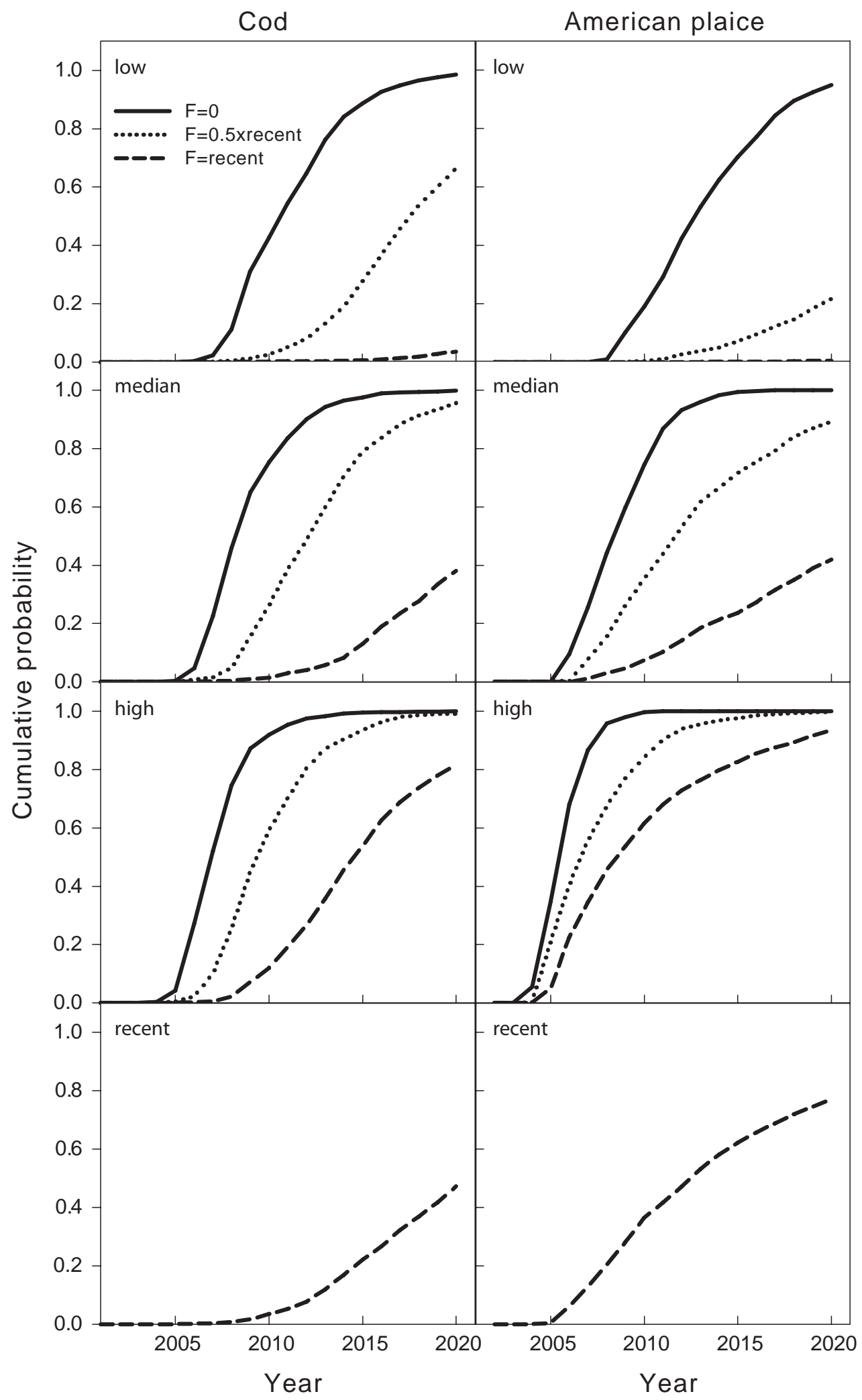

Fig. 9. The cumulative probability of the population exceeding $B_{\text {lim }}$ in each year at low, medium, high and recent levels of spawning stock biomass per recruit for 3NO cod and 3LNO American plaice. Random recruitment is generated from a non-parametric kernel smoother model. 


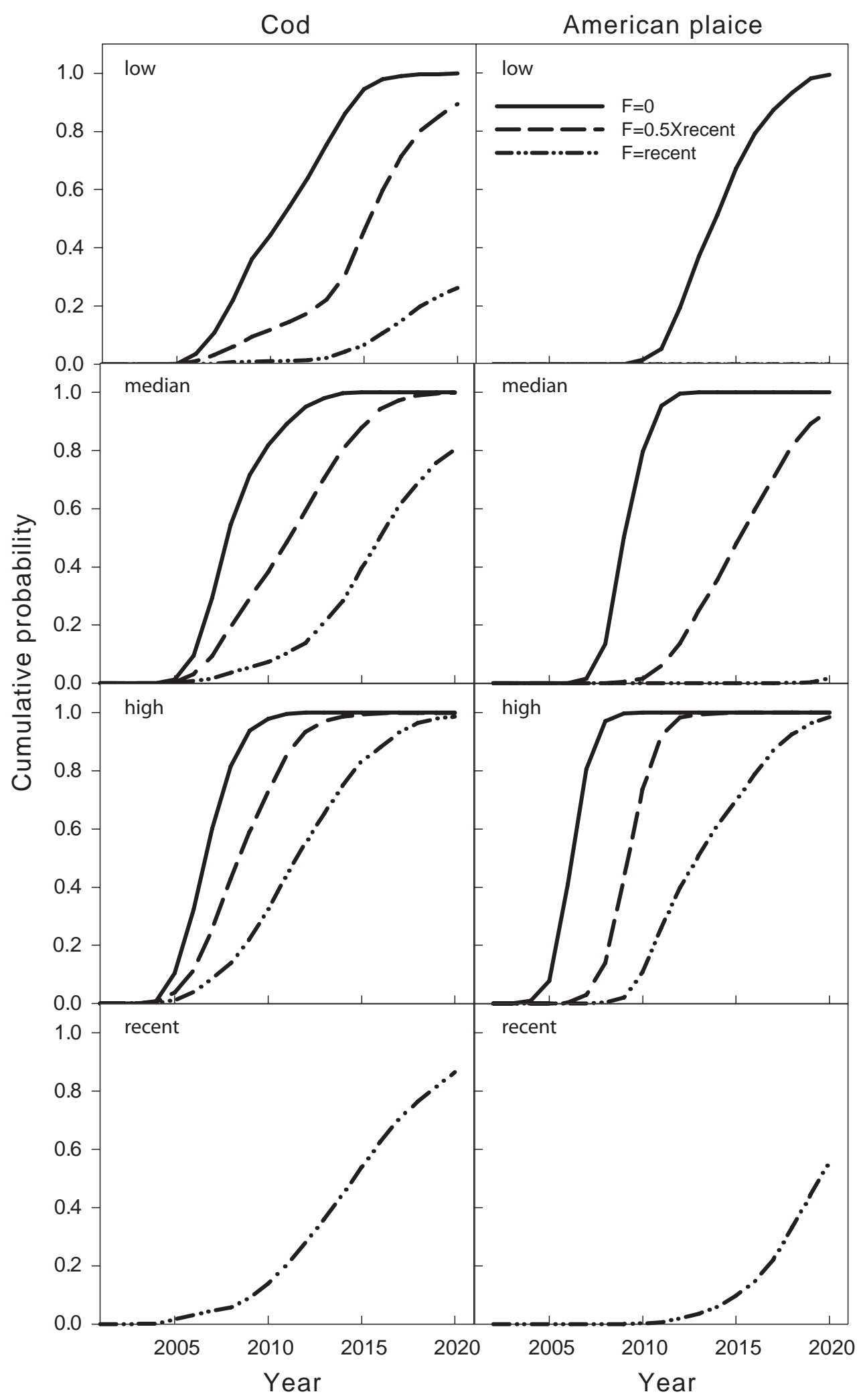

Fig. 10. The cumulative probability of the population exceeding $B_{\text {lim }}$ in each year at low, medium, high, and recent levels of spawning stock biomass per recruit for 3NO cod and 3LNO American plaice. Random recruitment is generated from a Beverton-Holt stock recruit model. 
SHELTON and MORGAN: Rebuilding of Cod and American Plaice Stocks
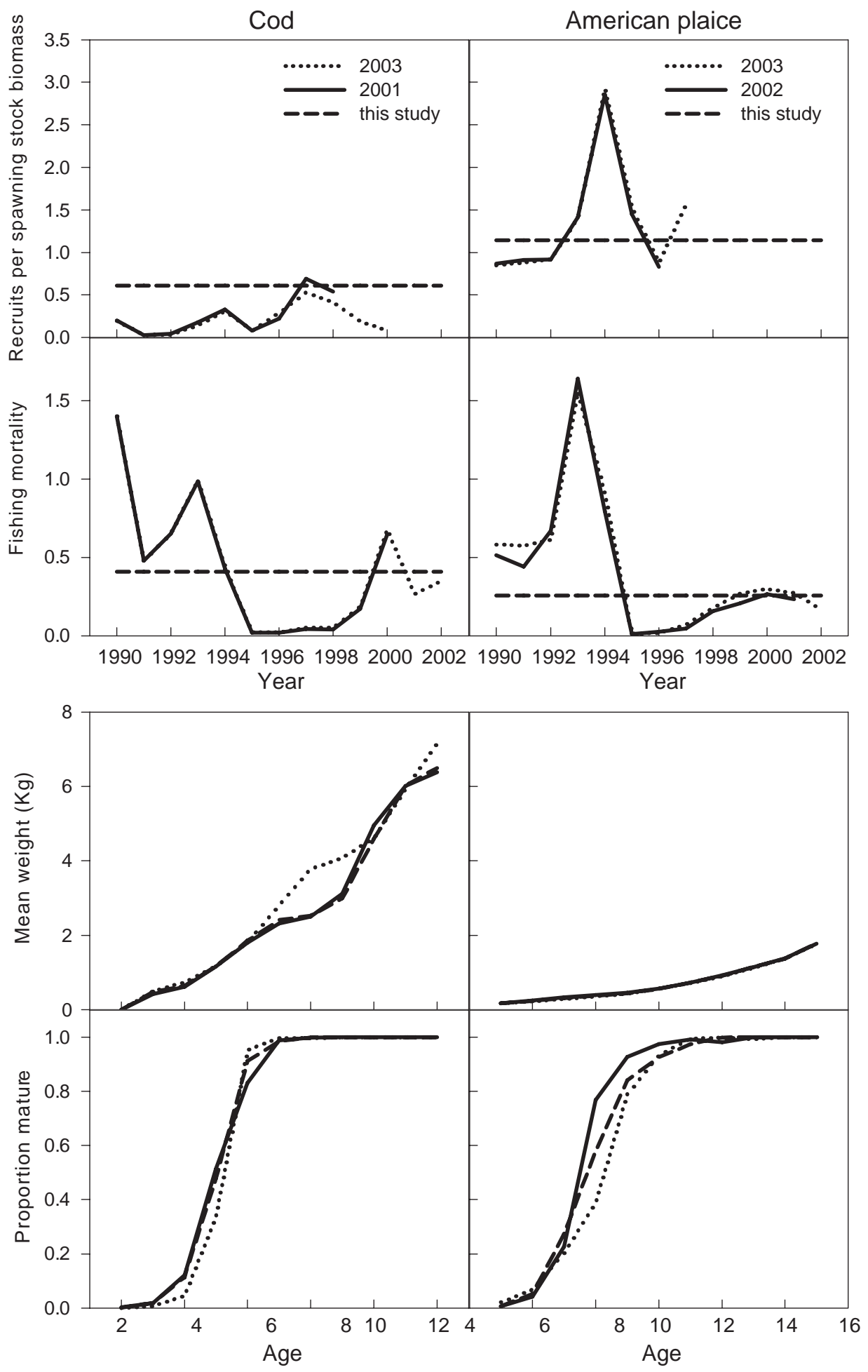

Fig. 11. Comparison of values of recruits per spawning stock biomass, fishing mortality, population mean weight, and proportion mature used in this study with those in the updated 2003 assessments for 3NO cod and 3LNO American plaice. For 3NO cod, values used in this study (broken line) were derived from the 2001 assessment (solid line), and should be compared with the 2003 assessment (dotted line). For 3LNO American plaice, values used in this study (broken line) were derived from the 2002 assessment (solid line), and should be compared with the 2003 assessment (dotted line). 
by-catches, it would appear that for Grand Bank American plaice stock in particular, there has been little effective enforcement of NAFO's CEM by-catch restrictions. The apparently greater degree of compliance with respect to southern Grand Bank cod may be a reflection of the very low biomass of this stock rather than effective enforcement of the $5 \%$ by-catch limit. Despite the by-catch restrictions, recent assessments of the two stocks reveal a creeping bycatch mortality problem reflected in an increasing trend in $F$. There are also indications that outside the 200 naut. mile zone, fishing may at times have been directed for both cod and American plaice (NAFO, 2001)

The results of the simulations are sensitive to the way in which recruitment was modelled. Nevertheless, the results are consistent across models in indicating a low to zero probability of attaining $B_{\text {lim }}$ by 2020 for both stocks under recent levels of by-catch $F$ and SPR. For 3NO cod, the probability of rebuilding to $B_{\text {lim }}$ by 2020 is zero under recent SPR and RPS conditions at the recent by-catch level of $F$, and is less than 0.5 under random recruitment generated from the kernel smoother model. However, the probability of rebuilding to above $B_{\text {lim }}$ exceeds 0.8 when random recruitment is generated from error around a Beverton-Holt model. For 3LNO plaice, probability of rebuilding to $B_{\text {lim }}$ by 2020 is also zero under recent SPR and RPS conditions at the recent by-catch level of $F$, but is about 0.8 applying random recruitment generated from the kernel smoother model, and about 0.6 using random recruitment generated from a Beverton-Holt model (i.e., a reversal of the results obtained for cod under the random recruitment models).

The fixed recruitment rate projections explored the combined effects of RPS and SPR on stock productivity; the results suggest that neither stock will rebuild to above $B_{\text {lim }}$ by 2020 at recent productivity levels - even if by-catch mortality is eliminated. Under median stock productivity conditions, the probability of rebuilding when $F=0$ is more optimistic for both stocks. If SPR and RPS are both at high levels for a sustained period, simulations applying a fixed recruitment rate indicate that continuing by-catch at recent levels will delay but not prevent rebuilding. However, the probability of sustained, simultaneously high SPR and RPS is unknown. Recent RPS is below the median for both stocks, and there is no evidence that a prolonged period of high RPS similar to that observed during the 1970s and early-1980s is in the offing. High recruitment rates in $3 \mathrm{NO}$ cod have not been observed for some time. Recruitment rates have been more variable in 3LNO plaice, with some high values observed during the last 10 years. Recent SPR is below the median for $3 \mathrm{NO}$ cod, but above the median for 3LNO plaice. For
3NO cod, there is thus some latitude for improvement in spawning stock biomass production, albeit primarily through increased weight increments at older ages as recent maturation rates are close to the maximum observed for the stock.

Results from the random recruitment simulations for both 3NO cod and 3LNO plaice give more optimistic rebuilding times compared to the fixed recruitment rate trials at low, median and recent SPR, but are more pessimistic at high SPR compared to fixed recruitment rate trials when both RPS and SPR are high. These results are consistent with the kernel smoother and Beverton-Holt models predicting higher than median recruitment rates at low spawning stock biomass.

The present study expands on those of Rivard et al. (MS 1999), Morgan et al. (MS 2002; MS 2003), and Healey et al. (MS 2003) by considering the effect of future stock productivity conditions (in combination with different levels of by-catch mortality) on stock rebuilding. The previous studies used only recent average weights and maturities in the projections and did not evaluate the effect of different recruitment rates. As in the present study, Rivard et al. (MS 1999) and Morgan et al. (MS 2002) included uncertainty in terms of estimates of numbers alive at the start of the projection period and in estimates of future recruitment. Recruitment uncertainty in these studies was simulated by resampling from past recruitment values using a non-parametric probability transition approach based on partitioning SSB into intervals (Getz and Swartzman, 1981). Rivard et al. (MS 1999) also treated recruitment in a similar way to the non-parametric kernel smoother approach used in the present study. For 3NO cod, the results of our study are more pessimistic than those in Rivard et al. (MS 1999). They obtained probabilities of greater than 0.6 of the stock rebuilding to above $B_{\text {lim }}$ by 2010 and probabilities of close to 1.0 that $B_{\text {lim }}$ would be attained by 2020. The greater pessimism in the present study primarily reflects the increase in by-catch $F$ that has taken place since the 1999 assessment, which is translated into a higher $F$ representing recent conditions in our simulation trials. For 3LNO plaice, our results are less pessimistic than those reported by Morgan et al. (MS 2002) [computed to the year 2012 based on similar data] as their simulated population became trapped in a low recruitment regime using the probability transition approach applied in their analysis.

The most recent NAFO Scientific Council assessments of 3NO cod and 3LNO plaice (Morgan et al., 2003; Healey et al., 2003) provide medium-term deterministic projections to 2008. These results are consistent with the 
results in our study based on recent stock productivity conditions. The NAFO Scientific Council projections indicate that SSB in both stocks will continue to decline under status quo $F$ and that neither stock would attain $B_{\lim }$ by 2008 under a $F=0$ scenario.

There is considerable uncertainty regarding future levels of productivity (in terms of RPS and SPR) of the cod and American plaice stocks on the Grand Bank. Productivity of fish populations can vary considerably as a consequence of both density-dependent and density-independent processes. Further, maturation rates, growth rates, recruitment rates and mortality rates (all of which determine population productivity) may not vary independently. For example, juvenile growth and maturation rates may be positively correlated (Chen and Mello, 1999; Morgan and Colbourne, 1999) and early maturation can actually lead to lower RPS (Kjesbu et al., 1996; Marteinsdottir and Thorarinsson, 1998; Trippel, 1998). Our simulations did not consider such dependencies, but these may be important in evaluating stock rebuilding prospects in the presence of by-catch mortality. We also did not consider the possible impacts of changes in natural mortality. If natural mortality rates are currently higher than assumed, then our simulations might be overly optimistic in terms of stock rebuilding.

Clearly, given our simulation results, prospects for stock rebuilding at recent by-catch levels are not good unless conditions (including recruitment rates) become highly favourable for stock growth. Under more average conditions, by-catch mortality will have to be substantially reduced or eliminated for either stock to rebuild. The random recruitment models indicate that rebuilding could take place more rapidly than predicted under fixed recruitment rates, but the random recruitment models over-predicted recruitment at low stock sizes for both stocks. When such model behaviour is combined with a wide probability distribution around the predicted values (driven in part by the variability in recruitment at high or intermediate SSB levels), the results can be misleading. Alternative random recruitment models might be explored to account for residual time dependence in recruitment variability or to incorporate functional responses that allow for depensation in recruitment at low SSB. However, these models are unlikely to give more optimistic results than those from the random recruitment models used in this study.

Although the simulations conducted in our study are not exhaustive with regard to the exploration of possible future scenarios, we feel that the trials bracket the range of likely outcomes. The conclusion that by-catch needs to be reduced to promote stock rebuilding is robust across the three treatments of recruitment used in our study, and has been a consistent conclusion of the recent NAFO stock assessments of 3NO cod and 3LNO plaice. Our simulations show that both stocks could rebuild under recent by-catch mortality levels if RPS and SPR were simultaneously high ( $90^{\text {th }}$ percentile of observed values). While there is an unknown but presumably low probability of such an event occurring, this scenario should not be given consideration in the development of rebuilding plans. Instead, to be consistent with the precautionary approach to fisheries management, rebuilding plans for the two stocks should be robust to the continuation of recent stock productivity conditions and even make allowances for poorer stock productivity conditions in the future.

Effective enforcement of the current by-catch regulations would likely markedly reduce $F$ on 3LNO plaice, and also reduce fishing mortality on $3 \mathrm{NO}$ cod. One way to achieve a reduction in by-catch mortality would be to increase the mesh size of the trawl gear, thereby allowing reduced capture and increased survival of young cod and American plaice. In a positive step towards multispecies management, the regulated mesh size in the NAFO NRA skate fishery was increased from $130 \mathrm{~mm}$ to $280 \mathrm{~mm}$ in 2002 (NAFO, 2002). This fishery appeared previously to be a major source of cod and American plaice by-catch on the Grand Bank. It is too early to determine if the expected reduction in by-catch mortality has been realised.

The importance of accounting for and controlling by-catch mortality has increased as traditional targets of directed fishing have declined or collapsed. Of major concern is the incentive for fleets to "top off" to the bycatch limit through directed fishing on by-catch species, especially when these species are of high value (Ackley and Heifetz, 2001). In this situation, low by-catch rates can only be attained through strong and effective enforcement measures. The implications of continuing high by-catch mortality on depleted stocks needs to be effectively communicated to fisheries managers (Crowder and Murawski, 1998). In the simulation trials reported in this study, time to rebuild to above $B_{\text {lim }}$ was used as a performance measure. However, in terms of the precautionary approach, this is a relatively modest objective. It would be much more in keeping with a precautionary approach to measure the time to rebuild to a stock size level where the probability of being below $B_{\text {lim }}$ is very small and the stock can be considered to be within safe biological limits. If steps are not taken soon to substantially reduce by-catches, there appears to be little prospect for rebuilding of Grand Bank cod and American plaice to within safe biological limits. Recent by-catch levels of these two stocks are clearly 
not consistent with a precautionary approach to fisheries management (FAO, 1996; Scientific Council, 2003).

\section{Acknowledgements}

We thank the many people involved in the collection of the data used in this study. B. Healey, M. O'Connell, J. Brattey, S. Cadrin and anonymous reviewers gave helpful comments on earlier versions of the manuscript. An Associate Editor of the Journal of Northwest Atlantic Fisheries Science is thanked for considerable editorial assistance leading to a substantial improvement of the manuscript.

\section{References}

ACKLEY, D. R., and J. HEIFETZ. 2001. Fishing practices under maximum retainable by-catch rates in Alaska's groundfish fisheries. Alsk. Fish. Res. Bull., 8: 22-44.

ALVERSON, D. L., M. H. FREEBERG, J. G. POPE, and S. A. MURAWSKI. 1994. A global assessment of fisheries by-catch and discards. Rome, FAO. FAO Fish. Tech. Pap., 339: 233 p.

ANON. MS 2003. Report of NAFO Scientific Council Workshop on the Precautionary Approach to Fisheries Management. NAFO SCS Doc., No. 5, Serial No. N4805, 56 p.

ATKINSON, D. B. 1994. Some observations on the biomass and abundance of fish captured during stratified-random bottom trawl surveys in NAFO Divisions $2 \mathrm{~J}$ and $3 \mathrm{KL}$, autumn 1981-1991. NAFO Sci. Coun. Studies, 21: 43-66.

CHEN, Y., and L. G. S. MELLO. 1999. Growth and maturation of cod (Gadus morhua) of different year-classes in the northwest Atlantic, NAFO subdivision 3Ps. Fish. Res., 42: 87-101.

CROWDER, L. B., and S. A. MURAWSKI. 1998. Fisheries bycatch: implications for management. Fisheries, 23: 8-16.

DEL RIO, J. L., and S. JUNQUERA. MS 2001. Spanish skate (Raja radiata Donovan, 1808) fishery in the Grand Bank (NAFO Division 3N): 1997-2000. NAFO SCR Doc., No. 31, Serial No. N4408, 10 p.

DEL RIO, J. L., P. DURAN MUNOZ, A. VAZQUEZ, H. MURUA, E. ROMAN, and F. GONZALEZ. MS 2002. Spanish research report for 2001. NAFO SCS Doc., No. 7, Serial No. N4623, 26 p.

DEL RIO, J.L., F. GONZALEZ, and D. GONZALEZ. MS 2003. The Spanish fishery (1998, 2000-2002) and the Spanish 3NO survey (1995-2002) in relation to the skate fishery in NAFO Divisions 3NO. NAFO SCR Doc., No. 29, Serial No. N4857, 16 p.

FAO. 1995. Precautionary approach to fisheries. Part 1: Guidelines on the precautionary approach to capture fisheries and species introductions. Elaborated by the Technical Consultation on the Precautionary Approach to Capture Fisheries (including Species Introductions). Lysekil, Sweden, 6-13 June 1995 (A scientific meeting organized by the Government of Sweden in cooperation with FAO). Rome, FAO. FAO Fish. Tech. Pap., 350 (Part 1): 52 p.

GAVARIS, S. MS 1988. An adaptive framework for the estimation of population size CAFSAC Res. Doc., No. 29, 12 p.
GETZ, W. M., and G. L. SWARTZMAN. 1981. A probability transition matrix model for yield estimation in fisheries with highly variable recruitment. Can. J. Fish. Aquat. Sci., 38: 847-855.

HALL, M.A. 1996. Strategic issues in managing fishery bycatches. In: Solving by-catch: considerations for today and tomorrow. Alaska Sea Grant College Program Report No. 96-03, University of Alaska Fairbanks, p. 29-32.

HALL, M.A., D. L. ALVERSON, and K. I. METUZALS. 2000. By-catch: problems and solutions. Mar. Poll. Bull., 41: 204-219.

HEALEY, B. P., E. F. MURPHY, D. E. STANSBURY, and J. BRATTEY. MS 2003. An assessment of the cod stock in NAFO Divisions 3NO. NAFO SCR Doc., No. 59, Serial No. N4878, 60 p.

KJESBU, O. S., P. SOLEMDAL, P. BRATLAND, and M. FONN. 1996. Variation in annual egg production in individual captive Atlantic cod (Gadus morhua). Can. J. Fish. Aquat. Sci., 53: 610-620.

KULKA, D. MS 2002. Description of the 2001 yellowtail flounder fishery on the Grand Banks with a comparison to past years. NAFO SCR Doc., No. 73, Serial No. N4686, 34 p.

MARTEINSDOTTIR, G., and K. THORARINSSON. 1998. Improving the stock-recruitment relationship in Icelandic cod (Gadus morhua) by including age diversity of spawners. Can. J. Fish. Aquat. Sci., 55: 1372-1377.

MORGAN, M. J. MS 2000. Estimating spawning stock biomass in 2J3KL cod using a cohort maturation model and variable sex ratio. DFO Can. Sci. Advis. Sec. Res. Doc., No. 110, $17 \mathrm{p}$.

MORGAN, M. J., and W. B. BRODIE. MS 2001. An exploration of virtual population analyses for Divisions 3LNO American plaice. NAFO SCR Doc., No. 4, Serial No. N4368, 20 p.

MORGAN, M. J., W. B. BRODIE, B. P. HEALEY, D. MADDOCK PARSONS, K. S. DWYER, and D. POWER. MS 2002. An assessment of American plaice in NAFO Div. 3LNO. NAFO SCR Doc., No. 70, Serial No. N4683, $68 \mathrm{p}$.

MORGAN, M. J., W. B. BRODIE, D. MADDOCK PARSONS, B. P. HEALEY, and D. POWER. MS 2003. An assessment of American plaice in NAFO Div. 3LNO. NAFO SCR Doc., No. 56, Serial No. N4874, 70 p.

MORGAN, M. J., and E. B. COLBOURNE. 1999. Variation in maturity at age and size in three populations of American plaice. ICES J. Mar. Sci., 56: 673-688.

MUSICK, J. A., S.A. BERKELEY, G. M. CAILLIET, M. CAMHI, G. HUNTSMAN, M. NAMMACK, and M. L. WARREN, JR. 2000. Protection of marine fish stocks at risk of extinction. Fisheries, 25: 6-8.

MYERS, R. A., J. BRIDSON, and N. J. BARROWMAN. 1995. Summary of worldwide stock and recruit data. Can. Tech. Rep. Fish. Aquat. Sci., 2024: 327 p.

NAFO. 2001. Scientific Council Reports 2001. NAFO, Dartmouth, NS.

2003. Scientific Council Reports 2002/2003. NAFO, Dartmouth, NS, p. 175.

2004. NAFO Conservation and Enforcement Measures. NAFO FC Doc., No. 1, Serial No. N4936.

RICE, J. C., and G. T. EVANS. 1988. Tools for embracing 
uncertainty in the management of the cod fishery in NAFO divisions 2J+3KL. ICES J. Cons., 45: 73-81.

RIVARD, D. 1982. APL programs for stock assessment (revised). Can. Tech. Rep. Fish Aquat. Sci., 1091: 146 p.

RIVARD, D., P. SHELTON, and D. STANSBURY. MS 1999. Evaluating recovery time from long-term projections including uncertainties: an example for cod on Southern Grand Banks (NAFO Divisions 3NO). NAFO SCR Doc., No. 67, Serial No. N4126, 18 p.

SCIENTIFIC COUNCIL. 2003. Proposed NAFO Precautionary Approach Framework. NAFO SCR Doc., No. 23, Serial No. N4900, 5 p.

SHELTON, P. A. 1998. A comparison between a fixed and a variable fishing mortality control rule used to manage the cod stock off southern Labrador and the east coast of Newfoundland. Fish. Res., 37: 275-286.

SINCLAIR, A. F., and S. A. MURAWSKI. 1997. Why have groundfish stocks declined? In: J. Boreman, B. S. Nakashima, J. A. Wilson, and R. L. Kendall (eds.). Northwest Atlantic groundfish: perspectives on a fishery collapse. Bethesda, Maryland. Am. Fish. Soc., p. 71-93.

STANSBURY, D. E., P. A. SHELTON, E. F. MURPHY, B. P. HEALEY, and J. BRATTEY MS 2001. An assessment of the cod stock in NAFO Divisions 3NO. NAFO SCR Doc., No. 72, Serial No. N4450, 64 p.

TRIPPEL, E.A. 1998. Egg size and viability and seasonal offspring production of young Atlantic cod. Trans. Amer. Fish. Soc., 127: 339-359.

VARGAS, J., R. ALPOIM, E. SANTOS, and A. M. AVILA DE MELO. MS 2003. Portuguese research report for 2002. NAFO SCS Doc., No. 7, Serial No. N4815, 53 p.

VARGAS, J., R. ALPOIM, E. SANTOS, and A. M. AVILA DE MELO. MS 2004. Portuguese research report for 2003. NAFO SCS Doc., No. 5, Serial No. N4949, 50 p. 
